\section{ESRO's Public Reputation}

THIs week Nature has been talking to several scientists who, one way or another, have been involved in the affairs of the European Space Research Organization, and a broad picture has emerged of attitudes to the organization and to international cooperation in space research in general. Given that the Science Research Council spent $£ 4.5$ million on ESRO in 1967-68, which amounts to some 12 per cent of the funds which are the chief source of finance for basic research in Britain, scientists in other disciplines are likely to take a poor view of the debacles which have been a feature of European space projects almost since the idea of cooperation was first mooted at the beginning of the decade. Astronomers, for example, stand to gain as much from rocket and satellite experiments as scientists involved in studies of the near-Earth environment have done already, yet there is a lurking fear that whatever gains European space scientists have had out of ESRO have been at the cost of less support for astronomy.

No one complained about the quality of the technical work carried out by ESRO. Rather the organization's faults are seen to have their origin in political and economic problems. One scientist pointed out that when the foundations of ESRO were laid in 1960, there was hardly any indigenous space research in Europe, only in France and the United Kingdom. European states joining the organization did so not so much to do scientific research but for other reasons-prestige, the politics of European collaboration, the contracts which might be obtained, the spin-off from space research. ESRO is much healthier now than it was then because these views are out in the open, and in fact some of the conflicts have been reconciled by moves towards the applications of space research.

Such a change of direction is hardly likely to resolve ESRO's problems, however much it might please Italy and Belgium. For one thing, there is no obvious launcher for the type of communication satellite which would be a worthwhile investment and an obvious application of space technology. And the United Kingdom would have to be certain of a worthwhile return from any proposed application of the expertise in space techniques built up in Europe.

A combination of scientific research and technological applications would also please Professor $\mathrm{H}$. Elliot of Imperial College, London, who has experiments on the satellite ESRO 2 now orbiting, and is heavily committed to the HEOS satellite project. This means using rocket and satellite experiments to train scientists who will eventually move into the applications of space technology.

Comparison is inevitable between ESRO and the European organization devoted to nuclear physics (CERN). Despite recent setbacks arising from the British refusal to help build a $300 \mathrm{GeV}$ accelerator and the withdrawal of Spain from the organization at the end of this year because of foreign exchange problems, CERN is widely considered an example of successful European cooperation. The essential difference between CERN and ESRO, in Professor Elliot's view, is that the nations in CERN started out with the avowed intention of building the $300 \mathrm{GeV}$ proton synchrotron, whereas ESRO only had a nebulous idea of doing some space research. ESRO was right, all the same, to tackle ambitious projects; otherwise there would have been little incentive to join the organization. Professor Elliot supposed that perhaps ESRO should have agreed at the start what its aim was-to build and launch the large astronomical satellite, for example. On the other hand, Professor T. Kaiser of the University of Sheffield pointed out that any group with a legitimate claim is eventually able to use the accelerator at Geneva, but only a very limited number of states can participate with experiments in a satellite which represent a major investment for ESRO.

How do scientists fare in day-to-day dealings with ESRO ? Professor F. G. Smith of the Nuffield Radio Astronomy Laboratories has a dismal story to tell which began four years ago with a proposal submitted to ESRO for a radio astronomy experiment. Apart from some difficulty in deciding which of ESRO's ad hoc groups should examine the proposal (ESRO has no group unambiguously devoted to radio astronomy), Professor Smith heard nothing more of his proposal, and no one can be surprised if he now finds groundbased radio astronomy a sufficiently challenging field. At Leicester University, Dr K. A. Pounds talked of the frustrations experimenters have to endure because of the difficulties in which ESRO is enmeshed. The X-ray astronomy group at Leicester, for example, has built a major experiment which was to have flown in the TD 2 satellite cancelled earlier this year. Since then, ESRO has made a number of attempts to rescue the satellite, each of which has had to be examined in detail by the Leicester group, already committed to a heavy programme. Earlier this week, however, the outlook for TD 2 was less gloomy, and the hope is that the work put in by experimenters such as the Leicester group is not in vain.

Most of the space scientists Nature contacted recognized that British scientists are not getting a fair return from ESRO. It scems true to say that the Science Research Council's investment in the organization is enough to double the British rocket research programme, with the bonus of a small satellite launched every two or three years. That is, of course, if the ESRO subscription were to go entirely on the national programme, admittedly an unlikely prospect if Britain were to withdraw from the organization.

Some say that cooperation with NASA is far easier than with ESRO, with virtually no risk that wholesale cancellation will be the outcome of years of development work. But nobody believes that increased cooperation with NASA is an answer to their problems. For one thing, the feeling is that Britain, with its aim of closer ties with Europe, can hardly opt out of ESRO after rocking CERN's boat and delivering what may well turn out to be the coup de grace to ELDO. Another fear is that mounting pressure on the American science budget means that NASA will not be so inclined to launch satellites for Britain as it has been in the past. This message may have been brought to London this week by NASA representatives dealing with forthcoming Ariel satellites. It seems clear enough that British scientists' interests are best served by international cooperation involving some kind of revamped ESRO. 